\title{
ENTRE SABERES E CRENÇAS: O MUNDO ANIMAL NA IDADE MEDIA
}

\author{
Maria Eurydice de Barros Ribeiro** \\ maycebarros@gmail.com
}

RESUMO: Há alguns anos os historiadores se lançaram ao estudo das relações do homem com os animais. No que concerne aos medievalistas, desde o trabalho pioneiro de Robert Delort, a bibliografia sobre os animais não cessa de crescer. As fontes de diversas naturezas, manuscritas ou iconográficas, permitem detectar que o interesse dos medievais pelas bestas foi intenso e se revelou de diversas formas. Dentre uma vasta literatura produzida no medievo voltada para os animais, se distingue os bestiários por reproduzirem com equilíbrio, o saber e a crença.

Palavras Chaves: História dos animais, bestiários, saber na Idade média.

Em 1928, Montague Rhodes James estabeleceu uma classificação dos bestiários latinos. A partir de então, o interesse dos historiadores pelos animais, em particular dos medievalistas, têm-se mostrado constante. Em 2005, Baudoim Van Den Abeele (2005, p.283-300) deu continuidade ao levantamento bibliográfico estabelecido por W. B. Clark e M.Mc Munn (1989), chamando atenção para o crescimento da pesquisa relativa aos bestiários. Nos anos 80, do século passado, Robert Delort lançou um livro, cujo título possui a força de uma afirmativa: Animaux ont une histoire (DELORT, 1984).

O presente estudo começa com uma questão: Afinal, o que se sabia no medievo sobre o mundo animal? A primeira observação que se impõe é evidente: Em uma sociedade profundamente religiosa e mística, admitia-se, sem questionar, que os animais são parte da criação divina. Todavia, de acordo com o texto bíblico a criação teve como fundamento uma hierarquia, na qual o homem é a mais importante das criaturas. Feito a imagem e semelhança de Deus, toda a natureza foi criada para servilo: "Eu vos dou todas as árvores que dão frutos que dão semente: isto será vosso alimento. A todas as feras, a todas as aves do céu, a tudo que rasteja sobre a terra e que é animado de vida". (Gen.1-30)

\footnotetext{
* Professora associada da Universidade de Brasília. Doutora pela Universidade de Paris X Nanterre 
À crença da criação bíblica dos animais, somaram-se outras questões: Os animais seriam dotados de alma, inteligência, sensibilidade, emoções? Para os homens daquela época parece que sim, segundo testemunham os bestiários. Todavia a literatura medieval sobre animais é muito mais rica, integrando também outros livros tais como, as enciclopédias, os tratados, os livros de caça. Estas fontes tornam possível identificar o interesse que a idade média possuía sobre os animais desde os primeiros séculos. Inicialmente, a abordagem do mundo animal foi mais naturalista, complementando ou misturando a fonte bíblica com a tradição clássica. O saber sobre os animais buscou então, inspiração em uma compilação alexandrina, O Fisiólogo, cujo período é motivo de controvérsia entre os especialistas. Todos, porém, concordam sobre o conteúdo. O Fisiólogo consistia em um repertório de animais, plantas e pedras, interpretados de forma simbólica fornecendo elementos para a doutrina e a moral cristãs. Este manuscrito, originalmente em grego, foi exaustivamente, compilado e traduzido em diversas línguas orientais. Calcula-se, que entre os séculos V e IX foi traduzido para o latim. Rapidamente, ao que parece, extraiu-se do Fisiólogo, um bestiário, assim nomeado por se destinar apenas as bestas. Isto é, aos animais de quatro patas, as serpentes e a alguns animais marinhos. Um tratado semelhante, foi constituído pelas aves.

Mais tarde, no século XIII as chamadas enciclopédias classificaram os animais em grandes ordens. Porém, convém não exagerar a importância destes textos com relação aos bestiários que lhes antecedem. É necessário considerar, que o uso da palavra enciclopédia constitui um anacronismo para o medievo. De acordo com $\mathrm{Du}$ Cange, o termo em latim se manifesta no início do século XVI, a partir do grego, enkuklios paideia. Logo, a palavra, enciclopédia, não existia na idade média. Segundo Jacques le Goff (LE GOOF, 1994, p. 25) o historiador deve procurar legitimar o emprego da palavra enciclopédia, antes de fazer uso de um termo equivalente da sua própria época. Bernard Ribémont buscando a compreensão da palavra identificou três caminhos presentes na obra dos autores do século XIII: o legado da antiguidade, a organização do saber e a reflexão do autor presente no prólogo (RIBEMONT, 1995, p.235-236).

O século XIII, foi, portanto, sem dúvida, o grande momento das enciclopédias: O Speculum naturale de Vicente de Beauvais, o De proprietatibus rerum de Bartolomeu, o Inglês e o Livro do Tesouro de Bruneto Latini, tiveram várias traduções espalhando-se pelo ocidente europeu. Esta literatura enciclopédica difere 
profundamente, da literatura dos bestiários não só no enunciado mas, sobretudo, por manifestar um interesse pela fisiologia animal e humana. Além da teoria dos humores, repetida seguidamente, outras fontes cuja natureza pode ser considerada mais científica, que moral ou doutrinária, aparecem com frequência: Avicena, Galeno, João Damasceno, Isaque, Hipócrates. Todavia, a referência à Patrística encontra-se também presente com Agostinho e Basílio. Sem dúvida o que distingue as enciclopédias é o fundamento que estas buscam em Aristóteles substituindo a Bíblia, imprimindo uma visão do mundo animal, antropocêntrica. Enfim, enunciando a natureza dos animais, sistematizando o saber sobre os mesmos, classificando-os em ordens. Todavia, ainda assim, encontram-se referências aos dragões de Plínio, ou a descrição das sereias.

Um dos aspectos que separa as enciclopédias dos bestiários consiste, na significação moral da natureza que os últimos buscam. Este aspecto faz dos bestiários uma referência reveladora do espírito que norteia o saber medieval ao promover a imbricação da descrição com a explicação simbólica. A primeira, proveniente da Antiguidade e de Isidoro de Sevilha, a segunda, das Escrituras. Para tal, os bestiários serviram-se da metáfora objetivando a doutrinação cristã do homem. A tradução do latim para o vernáculo atesta a importância que este tipo de literatura possuía para os medievais.

Por volta de 1220, o Conde Roberto de Dreux encomendou a Pierre de Beauvais a tradução para o vernáculo do Fisiólogo, escrito originalmente, em grego. $\mathrm{O}$ conde exigiu que a tradução fosse feita em prosa e sem rimas, pois pretendia assegura-se da verdade que as palavras escolhidas para um poema poderiam esconder. Beauvais atendeu a ordem, com presteza: dentre os textos da época, a sua versão é considerada a mais próxima da fonte original. O início da tradução é revelador do que seria a essência dos bestiários:

Aqui começa o bestiário retirado dos propósitos dos filósofos antigos. Aqui começa o livro que se denomina Bestiário, assim chamado porque ele trata das naturezas das bestas. Ora, o conjunto das criaturas que Deus colocou na terra. Deus as criou para o homem, com a finalidade que este seguisse o seu exemplo de crença religiosa e de fé. (BEAUVAIS, 1980, p.19)

A primeira informação que Beauvais traduz é uma afirmativa: o bestiário foi "retirado dos propósitos dos filósofos antigos". Embora, aparentemente, simples, essa informação tem confundido os editores contemporâneos dos bestiários, que, ao longo 
do século XX, referiram-se ao Fisiólogo, como um autor anônimo, o "naturalista". O equivoco deve-se, igualmente, a Pierre de Beuavais que tratou o Fisiólogo, como "o bom clérigo de Atenas".

Segundo Gaston Duchet-Suchaux, (DUCHET-SUCHAUX, 1992, p.10) Pierre de Beauvais enganou-se ao julgar que o Fisiólogo fosse uma pessoa (o bom clérigo de Atenas), pois é possível identificar no texto vários filósofos da antiguidade, tais como Aristóteles, Plínio, o Velho e Plutarco. As controvérsias não param aí. Um outro ponto diz respeito a datação da obra: enquanto a maioria dos autores indica o século II, outros, se referem ao século III ou mesmo ao século IV ( No entanto, todos são unânimes quanto a procedência do texto: composto em Alexandria, em grego, essa espécie de enciclopédia do mundo animal real e fabuloso, é uma compilação de textos veiculados pelos autores da antiguidade. O mais antigo Fisiólogo (em grego) que se conheceu foi o Codex de Smirna (século IX), desaparecido em um incêndio em 1922. A tradução do grego para o latim teve início no século IV, sendo o exemplar latino mais antigo que sobreviveu até os nossos dias, datado do século IX (Berna, Ms.L, 318).

Nos primeiros anos do século XII, os primeiros manuscritos em latim e em anglo-normando reapareceram na Inglaterra sem que se conheçam as circunstâncias. Sabe-se, apenas, que tal empreitada deve-se a Phelippe de Thaon, que destinou o bestiário a predicação. Por volta de 1180, as catedrais de Lincoln e de York produziram muito exemplares de luxo, mas, geralmente os bestiários eram obras modestas. No início do século XIII alguns autores do norte da França, da Normandia, adaptaram o texto para a aristocracia, tal como, Pierre Beauvais.

Todos os bestiários medievais derivam, pois, de uma fonte comum: o Fisiólogo, o que permite concluir, que os autores medievais (dos bestiários) não tiveram acesso aos filósofos gregos citados no original e transladados para o vernáculo. O Fisiólogo foi assim, uma espécie de ponte que permitiu a passagem do saber da história natural grega para a idade média. Ao transmitir um saber zoológico em torno de aproximadamente, cinquenta espécies, viabilizou a classificação dos bestiários entre os livros que informavam a respeito dos animais. (DUCHETSUCHAUX, 1992: p.10-11). Dentre estes, dos animais de quatro patas - conhecidos por bestas - provém a denominação de bestiário. 
Dentro do mesmo espírito, as aves constituíram um livro a parte, o Livro das Aves. O primeiro exemplar de que se tem notícia, data de meados do século XII e é de autoria de Hugues de Fouilloy (traduzido para o português, como Hugo de Folieto). Escrito com letras góticas em latim (BNF ms.L 2495), o manuscrito ganhou várias versões que se espalharam pela Europa. W. B. Clark os classificou em cinco grandes grupos, dos quais, ao grupo da Abadia de Heiligenkreuz (Santa Cruz), na Áustria, pertencem os manuscritos portugueses. Consta que desde o final do século XII, os mosteiros portugueses possuíam pelo menos um exemplar do De avibus. Destes, três cópias chegaram até os nossos dias: o do Mosteiro Beneditino de Lorvão (Tombo, Ms.L - 1183), Santa Cruz de Coimbra, (ordem de Sto. Agostinho) século XII, (Porto) Santa Maria de Alcobaça (Cister). O manuscrito de Lorvão parece ser o mais conhecido. Foi provavelmente a partir dele, que a única tradução para o português que conhecemos foi estabelecida. Trata-se do Livro das Aves, um fragmento composto por nove fólios em pergaminho, escrita em minúscula do século XIV, que se encontra atualmente, no cofre da sessão de obras raras da Biblioteca Central da Universidade de Brasília. (BCE/Unb). O exame paleográfico do fragmento foi feito por Pedro de Azevedo que o datou e afirmou a sua autenticidade.

Conforme se afirmou, o texto original em grego é uma compilação de vários tratados de história natural da antiguidade, no qual os animais foram interpretados de forma alegórica objetivando a transmissão da moral cristã. Na tradução para o latim, foram mantidos os objetivos doutrinários, mas, o conteúdo foi adaptado, estimando-se que houve uma nova seleção dos animais representados. O bestiário constituiu-se, assim, em apenas, uma das formas de transmissão do saber, entre outras, sobre os animais. Dentre os textos que informavam sobre os animais, considera-se que as enciclopédia possuíam uma intenção "científica" que não deve ser, todavia, exagerada. $\mathrm{O}$ exame da tradição textual dos bestiários e do Livro das Aves, no quadro abaixo ajuda a compreender a imbricação do saber e crença.

\section{1/a Tradicão Textual dos Bestiários e do Livro das Aves Fisiólogo}

Texto em grego - século II

Tradução para o latim - século IV 
Tradução para o vernáculo - século XII

Anglo- normando - séc. XII Norte da França - séc. XIII

\section{$\underline{\text { 1/b Livro das Aves }}$}

Hugues de Fouilloy - Texto em latim - séc. XII

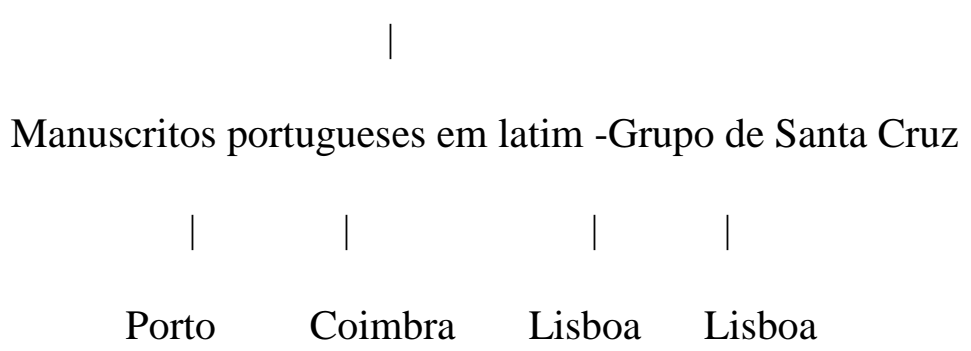

Lorvão

Brasília*

*Texto em português

Considerando-se que a cada transladação, o manuscrito medieval passava por alterações, podendo o monge ou copiar literalmente, conforme seu entendimento, ou interpretar o que estava lendo. Por isso, cabe colocar a seguinte questão: como após tantas transladações, a tradição clássica foi transmitida no século XIV, para a versão em língua portuguesa? Para responder, é necessário esclarecer as principais formas ou etapas que caracterizam o processo de transladação dos manuscritos medievais.

Lembre-se que inicialmente, o códex é portador de uma forma de saber. Entendendo-se nesse caso, não o conhecimento positivo ou científico como concebemos atualmente, mas, um conjunto de informações concretas relativas a determinado assunto, voltado para determinada finalidade. Neste contexto, o bestiário medieval integra-se ao conjunto de obras relativas ao conhecimento dos animais, 
embora se diferencie, conforme referência acima, das enciclopédias. Enquanto nestas últimas, procurava-se expor a natureza dos animais, os bestiários interpretavam esta natureza imprimindo valores positivos ou negativos, visando dar um sentido a vida humana voltado para a salvação da alma.

$\mathrm{Na}$ idade média, a compilação de textos é apenas, uma, dentre as possibilidades de transmissão do conhecimento ao lado da tradição oral, das representações figurativas, da exempla e dos sermões, apontados, grosso modo, como as principais vias de acesso ao saber e a crença. Nesta cultura, o bestiário se destaca como obra de predicação no auxílio da exegese, destinando-se aos mosteiros e a aristocracia. A larga difusão alcançada pelo gênero, que se espalhou por todo ocidente europeu a partir do século XII, evidencia que os bestiários transmitiam um saber considerado como necessário. Isto não significa que o conteúdo não tenha passado por modificações significativas que podem ser reveladas, entre outros aspectos, na seleção dos animais. Dos cinquenta, que segundo os estudiosos encontravam-se no Fisiólogo, o número foi restringido de forma variável, embora, algumas bestas, estivessem sempre presentes.

Ora, uma seleção é feita sempre em função das necessidades ou interesses de determinado grupo e de determinada época. Tais necessidades e interesses antes e depois do período de florescimento dos textos, não foram os mesmos. Logo, foi imperativo o desenvolvimento de técnicas de transladação e composição de textos, que, seguindo determinados critérios, se ajustassem as necessidades das principais ordens da sociedade medieval: o clero e a aristocracia. Embora o monge fosse antes de tudo um compilador, é importante compreender que na medida em que a compilação não era literal, introduziram-se formas técnicas no decorrer da compilação. Ainda que o conhecimento se restringisse a transmissão de um saber herdado (transladado), este podia ser elaborado tecnicamente, resultando em uma configuração textual que se apresenta como uma combinação de configurações mais antigas que são citadas nominalmente quer se trate das Escrituras, ou dos autores gregos. Este entrecruzamento de fontes da Antiguidade, explicita o reconhecimento da autoridade subjacente dos autores antigos. No caso do Livro das Aves, a autoridade dos antigos foi remetida a uma configuração precisa, o Fisiólogo, no qual, se haviam entrecruzado as Escrituras, fundamentando uma nova configuração textual: o bestiário (Ver quadro abaixo). 


\section{Fontes}

Autores antigos

Fisiólogo
Escrituras

Antigo Testamento - Novo Testamento

Bestiários<smiles>C=[IH]</smiles>

Livro das Aves

A estrutura da nova configuração textual ganhava geralmente, um prólogo original próprio à conjuntura da época. No prólogo escrito pelo autor anônimo da versão portuguesa, a obra é intitulada apropriadamente, assim como a nomeação das fontes e definição da natureza e dos objetivos do texto.

O exame filológico realizado pela edição crítica de 1956 concluiu que o texto foi traduzido a partir da cópia latina de Lorvão. O autor anônimo adaptou a versão as circunstâncias do seu século: O prólogo se distingue dos anteriores, sendo o único, entre os demais manuscritos, em que o autor usou o verbo trasladar, revelando que não pretende apenas copiar o manuscrito, (fazer a translatio) mas, transmitir um saber com base na tradição, (fazer a translaticius). Apesar deste esclarecimento, ele cumpre o mesmo procedimento dos seus predecessores:

... E, portanto, eu que este livro traslado do latim em linguagem não cuido de por nele o conhecimento que os Doutores da Teologia possuem expondo as autoridades da escritura santa (...) Nos por prazer somente poremos como dito é as propriedades que as aves e alguns outros animais têm. E assemelharemos aos costumes que os homens têm. (BCE, Ms.P, f.1) 
A versão portuguesa do manuscrito do século XIV, (BCE/Unb), está inserida na mesma tradição do manuscrito latino. Do fragmento sobreviveram onze tratados, dos quais, apenas um se encontra completo (o Tratado do Pavão). Em nenhum dos tratados consta qualquer alusão ao Fisiólogo, donde a necessidade de recorrer ao texto latino de Lorvão, composto de dois prólogos e cinquenta e seis capítulos (ver quadro abaixo).

\section{$\underline{\text { Livro das Aves }}$}

Lorvão

|

Prólogos -

Capítulos

\section{Brasília}

Prólogo

Tratados

1-11 Da pomba

12-14 Ventos

15-21 Do Falcão -

Do Falcão (2)

22-27 Da Rola e do pássaro -

Da palmeira e da rola

28 -33Do cedro e dos pássaros 34 Do Pelicano

35 Do Noitibó -

Do Noitibó

36 Do corvo -

37 Do galo -

Do galo

$38 \mathrm{Da}$ avestruz -

Da ema

39 Do Abutre -40 Do grou

41Do milhafre

$42 \mathrm{Da}$ andorinha -

Da andorinha

43 Da cegonha Da cegonha

44 Do melro - 45 Do mocho

46 Da gralha - 47 Do ganso

48 Da garça 49 Do carádrio

50) Da fênix 51 Da perdiz

52 Da codorniz 53 Da poupa 54

Do cisne 


\begin{tabular}{lc}
55 Do pavão & Do pavão \\
56 Da águia & Da Águia \\
\hline
\end{tabular}

De como Ezequiel o profeta pos a cada um dos evangelistas sua própria semelhança*.

* Fólio inexistente no original de Lorvão

No manuscrito de Lorvão, o Fisiólogo é citado literalmente nos tratados do Carádrio e da Poupa, capítulos 49 e 52. Em ambos, após breve apresentação da ave, segue-se a interpretação alegórica, conforme a citação abaixo do capítulo 49:

"O Fisiólogo diz que o carádrio é todo branco e que a parte interior da sua coxa tira as névoas dos olhos. Diz que a natureza do carádrio é tal que, se for levado algumas vezes para junto de um enfermo, mostra aos circunstantes se ele vai viver ou morrer'.

"Por carádrio entendemos Cristo, que veio ao mundo para salvar a humanidade. (...) Desvia, porém o rosto daqueles cujo coração reconhece impenitente. Rejeitou estes, mas, cura aqueles para quem volta o rosto". (GONÇALVES, 1999, p.59)

A ampla pesquisa que o manuscrito revela, permite constatar que $O$ Livro das Aves ganhou autonomia perante os bestiários, tornando-se um tratado exclusivamente sobre as aves, um Aviário, no qual Hugues de Fouilloy se dedicou a significação das aves mencionadas na Bíblia ou nos textos dos Pais da Igreja. O uso das Escrituras como fonte principal, foi sem dúvida, um critério importante para Fouilloy. Quando selecionou para o seu livro, apenas as aves, tornou-se um autor, no sentido medieval. Isto é, sem qualquer preocupação em buscar a originalidade, buscando apenas, reafirmar o que as autoridades já haviam dito; mas, de uma forma mais adequada a sua época.

Os clássicos não são citados diretamente, mas, indiretamente, não só, por meio do Fisiólogo, origem dos bestiários, mas, sobretudo, por meio das autoridades medievais, dos primeiros séculos que, por sua vez, recorreram a Plínio, Solino e Plutarco. No estudo mais recente sobre o Livro das Aves, Rémy Cordonnier em tese de doutorado defendida na Universidade de Lille (França, 2009) afirma que Hugues de Fouilloy renovou a literatura dos bestiários, promovendo a junção entre a mística do claustro e a escolástica nascente, concomitante, ao momento de transição da 
formação intelectual caracterizado pela introdução do pensamento de Aristóteles. Neste ambiente, sublinha Cordonnier, as novas práticas intelectuais exigiram uma observação mais precisa da natureza e do mundo animal. A mesma preocupação esta presente na compilação portuguesa mais antiga, proveniente do mosteiro de Lorvão. (ver quadro seguinte)

\section{Livro das Aves (Lorvão) - século XII}

\begin{tabular}{|c|c|c|c|c|c|c|c|}
\hline Bíblia & Fisiólogo & Beda & Gregório M. & Isidoro & \multicolumn{3}{|c|}{ Rábano Mauro } \\
\hline 98 vezes* & 2 vezes & $1 \mathrm{vez}$ & 6 vezes & 19vezes & \multicolumn{2}{|c|}{7 vezes } & \\
\hline & 1 & 1 & | & 1 & \multicolumn{2}{|l|}{ | } & \\
\hline & Filósofos & \multicolumn{2}{|c|}{ Plínio** } & & Plínio & e & Solino \\
\hline
\end{tabular}

O quadro acima permite observar que as fontes clássicas transmitidas foram a História Natural de Plínio, o Velho (livros VIII e XI, relativos a Zoologia) e Solino. Fontes do De Natura Rerum de Beda e das Etimologias de Isidoro de Sevilha. Como nenhuma compilação constitui um texto concluído e imutável, ao contrário, cada compilação é fundamentalmente, o ponto de partida de uma transmissão que modifica por sua vez, o saber existente, foi a partir dessas fontes, que as unidades textuais foram se formando, resultando de séries anteriores retomadas, onde a ideia subjacente que o discurso antigo é confiável foi mantida. (MELVILLE, 1998, p.33) É precisamente esta confiança nos clássicos que Isidoro e Beda transmitem. Embora, o fim último dos bestiários seja a doutrina cristã, a descrição dos animais é parte essencial do texto. Os animais, não são simples pretexto. A leitura alegórica tem fundamento no saber sobre os animais. Os bestiários não apresentam todos os animais, e sim uma seleção que levou em conta o valor simbólico de cada animal.

$\mathrm{Na}$ seleção das aves elaborada por Fouilloy o mesmo espírito foi observado. Guardando o caráter apologético próprio aos bestiários, ele procurou tanto na 
natureza, quanto nas Escrituras, a explicação do mistério da fé. Associando conhecimento sagrado e profano, foi deste último que extraiu as propriedades de cada ave, imprimindo significado simbólico para cada uma. A prioridade coube a pomba, única ave a ser mencionada no prólogo. A escolha privilegiada da ave revela a provável hierarquia do pássaro sem máculas. A ordem imposta aos pássaros foi repetida em todos os manuscritos. A versão tardia em português parece mais sucinta. Mas, ainda assim, seguindo a norma dos manuscritos anteriores, o autor introduziu a ave no prólogo e nomeou suas propriedades.

Na pomba, o saber sagrado e pagão foi sintetizado, passando pelo que Michel Pastoureau chamou de "estranha mutação." Isto é, na Antiguidade Clássica, a pomba estava relacionada a Vênus e como tal, simbolizava a volúpia. No Antigo Testamento, ela foi igualmente vinculada a beleza sublime, mas, sem qualquer relação com o sentido greco-romano. Ao contrário, como mensageira de Noé ela se tornou o símbolo da esperança, da paz e da harmonia, transmitindo, também, a ideia de pureza e simplicidade assimiladas, no Novo Testamento ao Espírito Santo. (PASTOUREAU, 2001, p. 30)

Aparentemente, o Livro das Aves distancia-se dos Bestiários, mais fiéis ao Fisiólogo. Se Fouilloy fez da fonte de origem, menor uso deve ter recorrido necessariamente a outras fontes para tratar da natureza das aves. Uma das fontes foi a Etimologias de Isidoro de Sevilha. No manuscrito de Lorvão, dos 56 capítulos, 17, o citam, dos quais, quatro, sobreviveram no fragmento da versão portuguesa: a águia, a andorinha, a cegonha e o pavão. Comparando-se a citação nominalmente, feita a Isidoro nos dois manuscritos, as diferenças são mínimas, embora a versão portuguesa, tenha simplificado o texto na sua totalidade.

Em Lorvão, o autor cita claramente a fonte em latim, Pauo, sicut Isidorus dicit - O pavão como diz Isidoro - recebeu o nome do som da voz. (Etimologias, XII,7,48) Na versão para o vernáculo, o monge traduziu literalmente: “O pavão, assim como diz Santo Isidoro, leva o nome do som espantoso que faz. Porque o pavão como se diz, faz pavor e espanto aqueles que o ouvem quando não são percebidos por estes." (BCE, ms.P f. )

Isidoro não é o único autor da Idade Média a ser citado. O manuscrito de Lorvão cita nominalmente, Beda, (uma vez) Gregório Magno (seis vezes) e Rábano Mauro (sete vezes). Em todos os textos, as interpretações de praxe têm como fonte a Bíblia, a mais citada dentre todas as fontes ( ver quadro seguinte). 


\section{BCE/Unb Livro das Aves (versão em português) - século XIV}

Ave

Fontes

Escrituras - AT. NT.

Pomba

Gênesis, Salmos, Cânticos dos Cânticos, Isaias

Mateus.

Falcão Gregório Job, Salmos, Cântico dos Cânticos, Paulo

Rola Salmos, Cânticos dos Cânticos. João.

Galo Gregório Números, Reis, Job

Ema

Andorinha Beda, Isidoro Tobias, Isaias, Jeremias

Cegonha Isidoro

Noitibó

Job, Salmos, Ezequiel, Mateus, Paulo Pavão

Isidoro, Reis

Águia Gregório, Isidoro Salmos, Jeremias, Ezequiel

De como Ezequiel o profeta pôs a cada um dos quatro evangelistas sua própria semelhança.

Se, por um lado, mantendo a tradição, o Livro das Aves submeteu à observação naturalista a interpretação simbólica; por outro, as mudanças recentes produzidas no ambiente intelectual, renovou a literatura de bestiários. A escolástica introduziu uma nova fauna constituída por feras e no caso das aves, por rapaces que se misturaram aos demais animais imprimindo ao simbolismo uma maior complexidade. No lugar de representar o Cristo, passou-se a representar um momento preciso da sua vida na terra, como a encarnação, o sacrifício na cruz, a ressurreição, ou a ascensão. A águia constitui um bom exemplo: ave de rapina, atributo de deuses (Zeus, Júpiter, Odin), teve o seu vôo associado ao momento da ascensão de Cristo (PASTOREAU, 2001, p. 45). 
Hugues de Fouilloy escreveu o Livro das Aves propondo uma moral, onde as virtudes, os vícios e os pecados capitais foram vinculados às aves. Para a transmissão dessa mensagem, recorreu às fórmulas mnemônicas, do seu tempo: apostando na memória visual, concebeu um método de ensino, no qual diagramas pedagógicos com imagens das aves ao alcance dos olhos conjugavam o texto a imagem. Ao mesmo tempo em que se beneficiou do contexto intelectual que vivia, contribuiu no processo caracterizado pela passagem do pensamento monástico para a escolástica.

A maior parte dos bestiários era iluminada com desenhos de animais estereotipados. Acredita-se que o modelo dos desenhos era copiado dos mosaicos antigos, uma vez que, muitas das espécies animais representadas não existiam no continente europeu. Todavia, com relação às aves, exceção feita àquelas provenientes da mitologia, as espécies eram geralmente conhecidas dos medievais. Logo, para concluir, é possível acrescentar que além da consulta das fontes bíblicas, dos autores da antiguidade clássica, e dos autores medievais, o autor do Aviário e os copistas e tradutores que o seguiram acrescentaram a observação, e assim contemplando o comportamento das aves, comprovaram ou descobriram um saber sobre as mesmas.

\section{BetweEn KNOWLEDGE AND BELIEFs: THE ANIMAL WORLD IN THE MidDLE AGES}

ABSTRACT: A few years historians have embarked on the study of men's relationships with animals. Regarding the medievalists, since the pioneering work of Robert Delort, the literature concerning animals continues to grow. Sources of several kinds, manuscript or iconographic, allow us to detect an intense interest of medieval men in beasts, and this interest has been revealed in several ways. Among a vast literature produced in the Middle Ages regarding animals we can distinguish the bestiary because they reproduce with balance, knowledge and belief.

Keywords: History of animals, bestiary, knowledge in the Middle Ages.

\section{ENTRE SABER Y CREENCIAS: EL MUNDO ANIMAL EN LA EDAD MEDIA}

RESUMEN: Hace algunos años los historiadores han embarcado en el estudio de la relación del hombre con los animales. En cuanto a los medievalistas, desde el trabajo pionero de Robert Delort, la literatura sobre los animales sigue creciendo. Las fuentes de diversas naturalezas, escritas a mano o iconográficas, pueden detectar que el interés de los medievales por las bestias fue intenso y se demostró de varias maneras. Entre una amplia literatura producida en la Edad Media hacia los animales, se distinguen los bestiarios, ya que producen, con equilibrio, el saber y la creencia. 
Palabras claves: Historia de los animales, bestiarios, saber en la Edad Media.

\section{REFERÊNCIAS}

CORDONIER, Rémy. Tese de Doutorado, Universidade de Lille (França), 2002

DELORT, Robert. Les Animaux ont une Histoire Paris: Seuil, 1984.

DUCHET-SUCHAUX, Gaston. Bestiaire romain. Paris: CIER, 1992.

LE GOFF, Jacques. Pourquoi le XIIIème siècle a-t-il été un siècle d'enciclopédisme?

In: M. Picone, L'enciclopedismo medievale, Ravenna : 1994.

Livro das Aves, Manuscrito português, século XIV, Biblioteca Central da Universidade de Brasília, Sessão de Obras Raras.

MELVILLE, Gert. Le problème des connaissances historiques au Moyen Age. Compilation et transmission de textes. In: Jean-Phillipe Genet. L'historiographie médiévale en Europe. Paris : CNRS, 1998

NETO, Serafim da Silva. Coleção de Estudos filológicos, n. 2, Rio de Janeiro: MECCasa Rui Barbosa, 1956.

PASTOUREAU, Michel. Les animaux célèbres. Paris: Bonneton, 2001.

RIBÉMONT, Bernard Les encyclopédies médiévales. Une première approche du genre. In: Pierre Guichard e Danièle Alexandre-Bidon. Lyon : Presses Universitaires de Lyon, 1995

VAN DEN ABEELE, Baudouin. Bestiaires medievaux. Nouvelles perspectives sur les manuscrits et les traditions textuelles, Louvain-la-neuve: 2005 
